\title{
Selective Cytotoxicity of Kaempferia parviflora Extracts in Human Cell Lines
}

\author{
Janpen Tangjitjaroenkun ${ }^{1}$, Waraporn Yahayo², Suangson Supabphol ${ }^{3}$, \\ Roongtawan Supabphol ${ }^{2 *}$
}

\begin{abstract}
Objective: Aims of this study were to (1) compare anti-proliferative activity between aqueous and ethanol Kaempferia parviflora (KP) extracts in both cancer (Human urinary bladder cancer cell, T24) and normal cell lines (Human umbilical vein endothelial cell, HUVEC). (2) confirm selective cytotoxicity of ethanol KP extract to normal and different cancer cell lines (3) investigate its cellular mechanism through $p 53$ and SIRT1 gene expression. Methods: Phytochemical difference between aqueous and ethanol extract was determined by thin layer chromatography (TLC). Screening for cytotoxic activity in human cell lines was performed by cell viability assay using 3-(4,5-dimethylthiazol2-yl)-2,5-diphenyltetrazolium bromide (MTT) reagent. P53 and SIRT1 gene expression were quantified using RT-PCR. Results: Results from the cell viability assay were shown as follows: (1) ethanol extract possessed higher toxicity to cancerous cells than aqueous extract (2) ethanol extract exhibited higher cytotoxicity to cancerous cells than normal cells (3) ethanol extract also showed cytotoxicity, with different levels, to three prostate cancer cell lines varying in aggressiveness. (4) ethanol KP extract induced cell death in T24 via p53 gene expression and prolonged cell survival in HUVEC through SIRT1 gene expression. Conclusion: These findings implied that ethanol KP extract might possibly be an alternative for cancer adjuvant therapy through the mechanism of selective $p 53$ and SIRT1 gene expression.
\end{abstract}

Keywords: Kaempferia parviflora- thin layer chromatography (TLC)- cell survival- p53- SIRT1

Asian Pac J Cancer Prev, 22, Anticancer Activity of Natural Compounds: HOW's on Methods and Reports Suppl, 73-79

\section{Introduction}

With the current cancer adjuvant therapy, undesirable side effects remain a concern as drugs do not specifically target cancerous cells. Many researchers have explored various kinds of targeted therapy. It has been reported that herbs can possibly be an option for target-specific drugs. One of the most interesting Thai traditional plants is Kaempferia parviflora (KP), categorized in the Zingiberaceae family, which is commonly known as black ginger or "Krachaidum". KP extract was considered safe with no alterations in human blood and urine chemistry parameters and has been used as a dietary supplement in traditional medicine for a long time (Wattanathorn et al., 2012; Promthep et al., 2015; Saokaew et al., 2017; Yoshino et al., 2018; Chivapat et al., 2018). Pharmacotoxic and histopathological effects were not reported in rats (Songpol et al., 2010). No genotoxicity is found in bacteria (Yoshino et al., 2019). Daily ingestion of KP extract is believed to safely reduce body fat composition, particularly abdominal fat, in Japanese overweight and pre-obese subjects. Dietary supplementation with KP extract has been reported to inhibit body weight rising, body fat accumulation, and glucose intolerance in both obese mice fed with high fat diet (Yoshino et al., 2014) and obese type II diabetic mice (Akase et al., 2011; Shimada et al., 2011; Matsuda et al., 2014).

Many pharmacological activities were previously mentioned including anti-proliferative effects in various cancer types, i.e. ovarian (Paramee et al., 2018), cervical (Potikanond et al., 2017), gastric (Kim et al., 2018), leukemic (Banjerdpongchai et al., 2008; Banjerdpongchai et al., 2009), bile duct (Leardkamolkarn et al., 2009), lung (Patanasethanont et al., 2007) and melanoma (Ninomiya et al., 2016) cancer cell lines. Furthermore, KP extract can also inhibit P-glycoprotein-mediated multidrug resistance (Patanasethanont et al., 2007a; Patanasethanont et al., $2007 b)$. These imply a promising opportunity of this herbal extract to be a supplements or potential agent in cancer adjuvant therapy. Methoxyflavones in KP have been claimed for physiological and pharmacological activities (Chen et al., 2018). A quality control assessment of KP raw materials and products was performed by a gas chromatography using 11 flavonoids as a

${ }^{1}$ Faculty of Science at Si Racha, Kasetsart University, Si Racha Campus, Chonburi, Thailand. ${ }^{2}$ Faculty of Medicine, Srinakharinwirot University, Bangkok, Thailand. ${ }^{3}$ Faculty of Medicine, Chulalongkorn University, Bangkok. Thailand. *For Correspondence: roongtawans@gmail.com 
reference (Sutthanut et al., 2007). Three main effective methoxyflavones, 3,5,7,3',4'-pentamethoxyflavone (PMF), 5,7-dimethoxyflavone (DMF), and 5,7,4'-trimethoxyflavone (TMF) are always mentioned for pharmacological effects (Chen et al., 2018). However, effects of KP extract in cancer cell lines with different levels of aggressiveness have never been reported yet.

This study is the first to compare the safety and cytotoxic effects of two KP extracts, aqueous and alcoholic extracts, in human cancer and normal cell lines. The extract with better cytotoxic effects would be selected for further cytotoxicity experiment in cancer cell lines varying in aggressiveness.

\section{Materials and Methods}

\section{KP extracts}

The black ginger rhizomes were purchased from Ratchaburi province, Thailand in December, 2017. KP rhizomes were identified by Dr. Wandee Gritsanapun, who retired from Department of Pharmacognocy, Faculty of Pharmacy, Mahidol University, Thailand. A voucher specimen (SWU-PY-1801) was kept at Department of Physiology, Faculty of Medicine, Srinakharinwirot University, Thailand. Processed with good manufacturing practices (GMP), rhizomes were assured by quality control of raw material. Dried KP rhizomes were mechanically powdered using electrical stainless steel blender, extracted with water thrice at room temperature, filtered and passed through spray drying process. For alcoholic extract, powdered rhizomes were extracted at room temperature with $95 \%$ ethanol thrice, filtered and concentrated as much as possible by a rotary evaporator. The percentage yield of aqueous and ethanol extract was expressed per 100 grams of dried rhizomes as 2.5 and $5 \%$, respectively. Both extracts were kept in amber bottles in the refrigerator.

\section{Chemicals and reagents}

All chemicals for cell culture were purchased from Gibco-BRL (NY, USA). All other chemicals used in this study were in analytical grade and purchased from SigmaAldrich Co (MO, USA).

\section{Thin layer chromatography (TLC)}

Phytochemical screening was performed by TLC technique. Ready-made TLC silica gel 60F254 from Merck (MA, USA), $5 \mathrm{~cm} \times 5 \mathrm{~cm}$ in size, as the stationary phase. Ethyl acetate was adopted as mobile phase. Quercetin and gallic acid were run in parallel with the extracts as phenolic and flavonoid standard compounds, respectively. After spotting two KP extracts and two reference compounds, the spotted TLC plate was then placed in a developing chamber containing ethyl acetate until the solvent front nearly reached the top of the plate. TLC plate was removed from the developing chamber and air-dried. Colored spots were visualized immediately under a hand-held ultraviolet (UV) lamp emitting short-wave (254 nm) and long wave (365 nm) UV light. Natural product (NP) solution was applied and visualized under 365-nm UV light.

\section{Cell lines and culture conditions}

Human urinary bladder cancer cell line (T24), three human prostate cancer cell lines, PC3, DU145, and LNCaP, as well as a non-cancer cell line, human umbilical vein endothelial cell (HUVEC), were purchased from American Type Culture Collection (ATCC). All were maintained in recommended culture media supplemented with $10 \%$ heat-inactivated fetal bovine serum, 100 units/ $\mathrm{mL}$ penicillin, and $100 \mu \mathrm{g} / \mathrm{mL}$ streptomycin, at $37^{\circ} \mathrm{C}$ in a humidified atmosphere of 5\% CO2 and 95\% air until $80-90 \%$ confluence. Cells are routinely sub-cultured twice a week.

\section{Cell viability assay}

To evaluate the safety and cytotoxicity of KP extracts in various cell lines, proliferation assay was performed using 3-(4,5-dimethylthiazol-2-yl)-2,5diphenyl tetrazolium bromide (MTT) as described previously (Yahayo et al., 2013). Briefly, each type of cells was sub-cultured in 24-well plates at a seeding density of $6 \times 10^{4}$ cells per well with full culture media until $80-90 \%$ confluence. Subsequently, cells were treated with serial concentrations of $\mathrm{KP}$ extract in a humidified atmosphere of $5 \% \mathrm{CO}_{2}$ at $37^{\circ} \mathrm{C}$ for 1,4 and 7 days. At the end of the incubation period, the cells were washed twice with phosphate-buffered saline followed by addition of and $150 \mu \mathrm{l}$ of culture medium containing $1.0 \mathrm{mg} / \mathrm{ml}$ of MTT was added into each well and further 3-4 h incubation. The media containing MTT was removed and the blue MTT-formazan product was extracted with acidified isopropyl alcohol. Absorbance of blue crystals was quantified spectrophotometrically at $570 \mathrm{~nm}$ using ELISA microplate reader (Biotex-synergy-HT). Percentage of survival was plotted against control (untreated) group. Each sample was assayed in triplicate.

Quantitative real-time polymerase chain reaction ( $q P C R$ )

After treatment with ethanol KP extract, cells were harvested and total RNA was isolated using TRIzol reagent (Thermo Fisher Scientific, Inc., USA) according to the manufacturer's instruction. Complementary DNA (cDNA) was synthesized from $1.0 \mu \mathrm{g}$ of total RNA using a SuperScript ${ }^{\mathrm{TM}}$ Reverse Transcriptase kit (Invitrogen, USA). P53 and SIRT1 gene expression was quantified by quantitative real-time PCR using CFX96 Touch Real-Time PCR Detection System (BIO-RAD, USA). Each reaction was repeated independent triplets.

The following primers were designed to detect $p 53$ and SIRT1 gene expression: p53: 5'-TTGCGTGTGGAGTATTTGGA-3' (forward) and 5'-AGTGGATGGTGGTACAGTCAG-3' (reverse); SIRT1: 5'-ACTGAAAAACCCCCACGAAC-3' (forward) and 5'-GCTGCTTGGTCTAAAAGTGTGA-3' (reverse); GAPDH: 5'-AGTCCACTGGCGTCTTCACC-3' (forward) and 5'-GTTCACACCCATGACGAACATG-3' (reverse).

\section{Statistical analysis}

All data are expressed as the mean of three independent experiments \pm standard deviation compared to the control group. Least squares linear regression analysis 
was done using Microsoft Excel to determine the $\mathrm{IC}_{50}$ values. Comparison between groups was performed by one-way analysis of variance (ANOVA) using SPSS IBM Singapore Pte Ltd (Registration No.1975-01566-C) following by the Student's t-test. Statistical significance is determined by $p$-value less than 0.05 .

\section{Results}

\section{Phytochemical study}

Organic compounds found in herbal extract mostly appear color, colorless or pale on the white TLC plate which are very difficult to localize the positions. These compounds can be visualized by either non-destructive or destructive process. Allowing compounds to remain in an unchanged form, non-destructive method can be easily done under UV light. To identify the existence of proper organic compounds, staining with proper reagents allow specific color to develop.
Selective Cytotoxicity of Kaempferia parviflora Extracts

This study firstly the first to view TLC plates under the UV light box (Camag UV Cabinet 4, USA). TLC plates can exhibit green fluorescence under short wave, $254 \mathrm{~nm}$, UV light. Absorbing short-wave UV, UV-active compounds will interfere fluorescence exhibition of the plates and appear as dark bands illustrated in Figure 1. This is called a mask effect. Ethanol KP extract completely expressed more bands than aqueous KP extract. It may be due to more organic compounds extracted by ethanol. Polyphenolics, such as gallic acid, and flavonoids, such as quercetin, might be found in both extracts in different concentrations.

Two KP crude extracts were separated by traditional TLC. Plates were visualized under UV light at 254 and $365 \mathrm{~nm}$ the results are shown in Figure 1. The existence of polyphenolic and flavonoid compounds in different concentrations can be seen in TLC chromatogram. These are going to be the fingerprint profiles for confirming the contents in each extraction. It can be very useful for

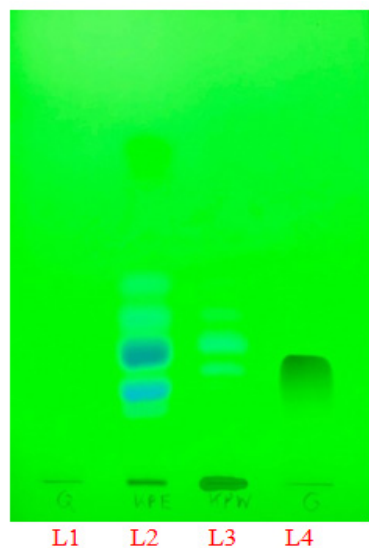

(a) UV (254-nm)

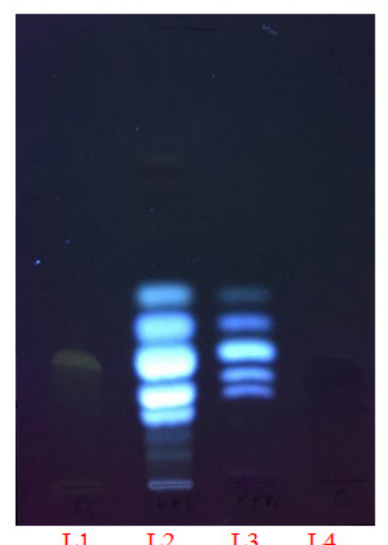

(b) UV (365-nm)

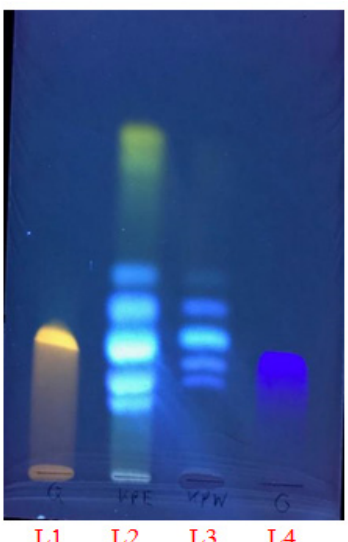

(c) NP (UV 365-nm)

Figure 1. TLC Chromatogram of Two Different KP Extracts Compared to Quercetin and Gallic Aid. Lane 1 (L1) = Quercetin $(0.1 \mathrm{mg} / \mathrm{mL})$; Lane $2(\mathrm{~L} 2)=$ Ethanol $\mathrm{KP}$ ethanol extract $(10 \mathrm{mg} / \mathrm{mL})$; Lane $3(\mathrm{~L} 3)=$ Aqueous KP aqueous extract $(10 \mathrm{mg} / \mathrm{mL})$; Lane $4(\mathrm{~L} 4)=$ Gallic acid $(1 \mathrm{mg} / \mathrm{mL})$

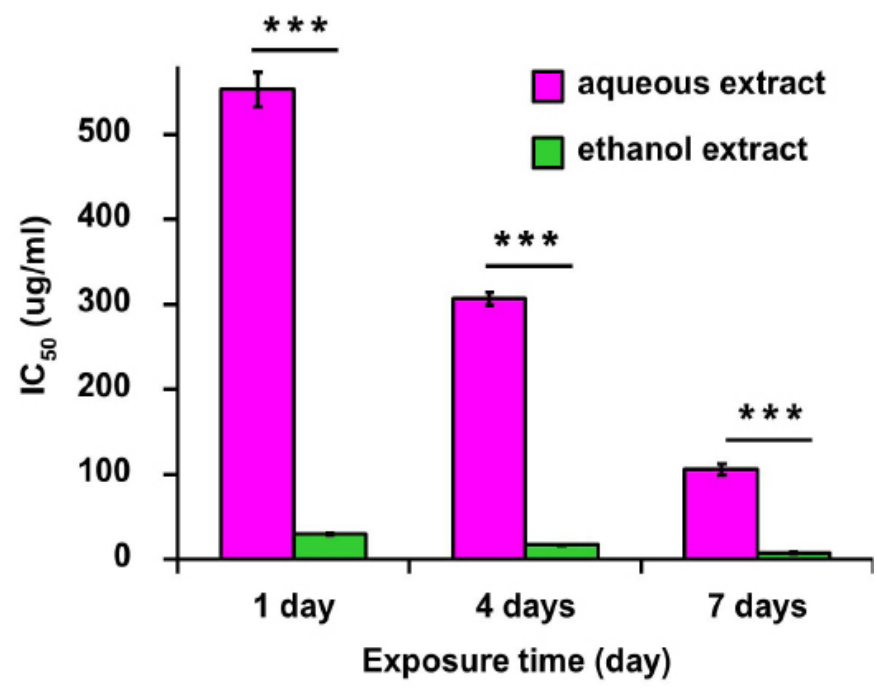

Figure 2. The Cytotoxicity of KP Extract in T24 was Determined by MTT Assay after Receiving Treatment 1, 4 and 7 days. The data are expressed in mean $\pm \mathrm{SD}$ of three independent experiments. Statistical significance is determined by $* * * \mathrm{p}<0.001$. 


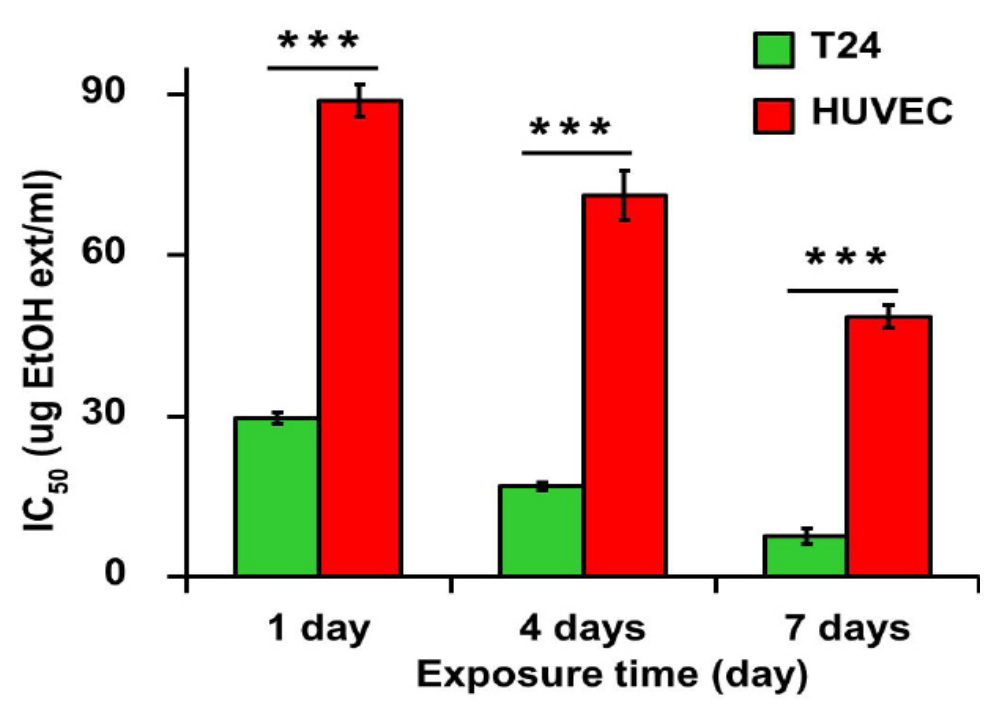

Figure 3. Cytotoxicity of Ethanol KP Extract in T24 and HUVEC was Determined after Receiving Treatment for 1, 4 and 7 Days. Data are expressed in mean \pm SD of three independent experiments. Statistical significance is determined by $* * * p<0.001$.

subsequent novel or previous studies with different batches of extracts to compare the result. Different physiological and pharmacological effects should be discussed under the fundamental of different phytochemical contents.

\section{Comparison of cytotoxicity between aqueous and ethanol} extracts

Cytotoxicity of aqueous and ethanol KP extract in human urinary bladder cancer cell line (T24) was determined by MTT assay after receiving treatment for 1, 4 and 7 days. Linear segment of the dose-response curve (\% survival and KP extract concentration) of three independent sample preparations was used to determine average $\mathrm{IC}_{50}$ values. Both aqueous and ethanol extract graphs show a dose- and time-dependent manner as illustrated in Figure 2. $\mathrm{IC}_{50}$ values of aqueous extract are $553.13 \pm 20.53,307.06 \pm 7.89$, and $106.06 \pm 6.66 \mu \mathrm{g} / \mathrm{mL}$ after 1, 4 and 7 days, respectively. In contrast, ethanol extract has a lower $\mathrm{IC}_{50}$ of $29.62 \pm 1.13,16.91 \pm 0.72$, and $7.56 \pm 1.45 \mu \mathrm{g} / \mathrm{mL}$ after 1,4 and 7 days, respectively $(\mathrm{p}<0.05)$.

Selective cytotoxicity in human urinary bladder cancer and endothelial cells

To identify its selective activity, cytotoxicity of ethanol KP extract in T24 and HUVEC was determined after receiving treatment for 1, 4 and 7 days in Figure 3. The responses of both cells are dose- and time- dependent fashion. $\mathrm{IC}_{50}$ values of HUVEC are $88.85 \pm 2.96$, $71.16 \pm 4.60$, and $48.53 \pm 2.13 \mu \mathrm{g} / \mathrm{mL}$ after 1,4 and 7 days, respectively. $\mathrm{IC}_{50}$ values of T24 are $29.62 \pm 1.13$, $19.61 \pm 0.72$, and $7.56 \pm 1,5 \mu \mathrm{g} / \mathrm{mL}$ after 1,4 and 7 days, respectively. $\mathrm{IC}_{50}$ value of HUVEC is approximately 3-7 times higher than of T24 $(\mathrm{p}<0.05)$.

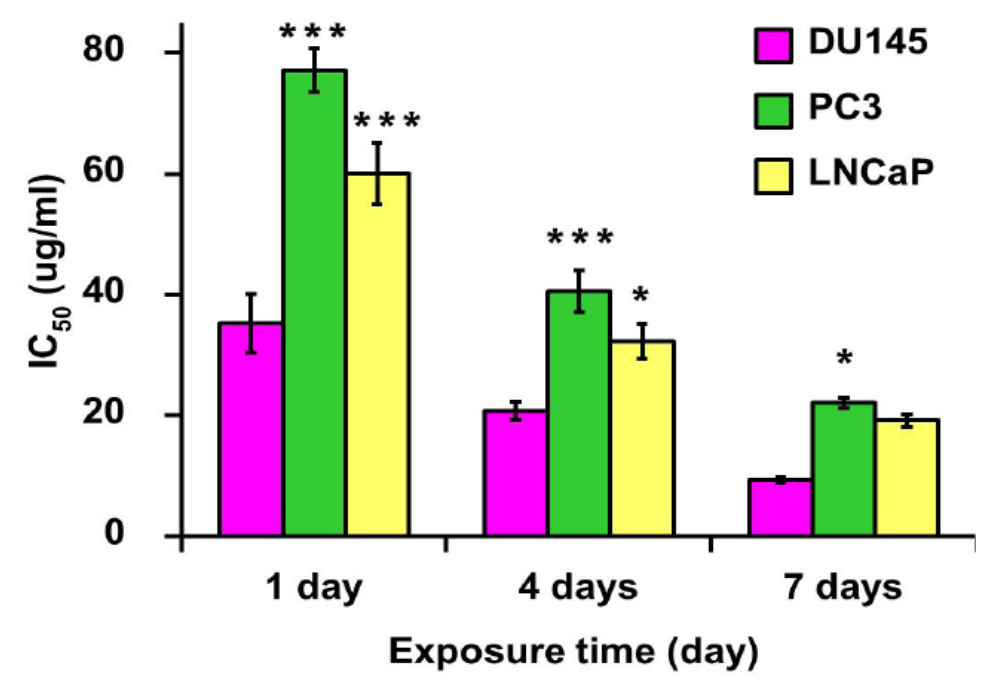

Figure 4. The Cytotoxicity of Ethanol KP Extract in Three Prostate Cancer Cell Lines was Determined after Receiving Treatment for 1, 4 and 7 Days. Data are expressed in mean $\pm \mathrm{SD}$ of three independent experiments. Statistical significance is determined by $* \mathrm{p}<0.05$ and $* * * p<0.001$. 


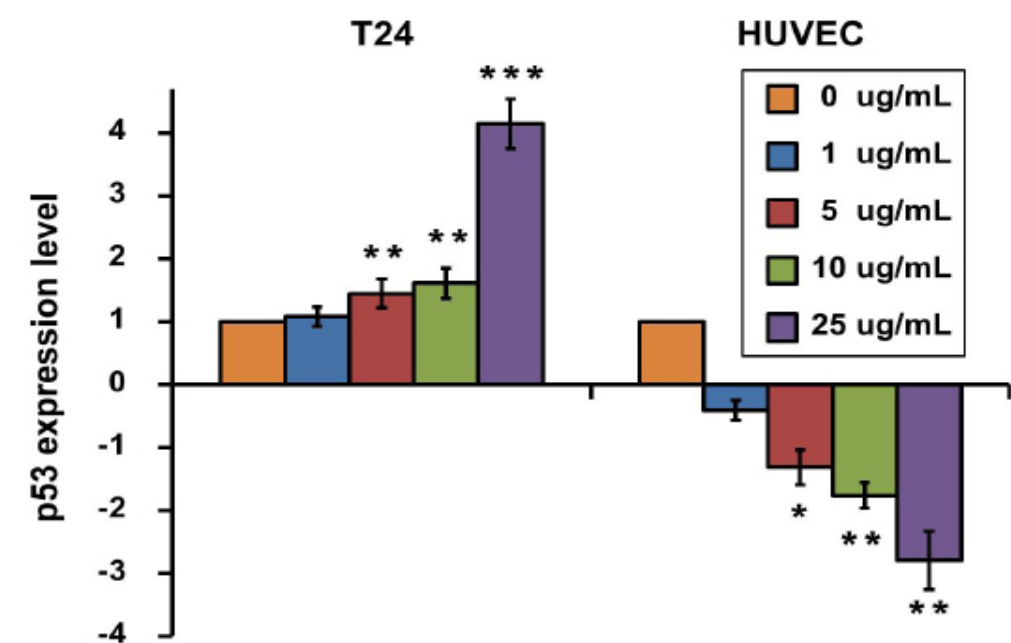

Figure 5. Cells Treated with Ethanol KP Extract for 4 Days Significantly Show Up-Regulation and Down-Regulation of $p 53$ Gene in T24 and HUVEC, Respectively. Data are expressed in mean \pm SD of three independent experiments. Statistical significance is determined by $* \mathrm{p}<0.05, * * \mathrm{p}<0.01$ and $* * * \mathrm{p}<0.001$.

\section{Cytotoxicity in different aggressive human prostate cancer} cells

Cytotoxicity of ethanol KP extract in three prostate cancer cell lines varying in aggressiveness is illustrated in Figure 4. Expressing a low level of androgen receptors, DU145 and PC3 are known to be poorly-differentiated androgen-independent. However, LNCaP, with a high level of androgen receptors, is classified as well-differentiated androgen-dependent.

Due to its lowest aggressiveness, $\mathrm{IC}_{50}$ value of DU145 is the least among three prostate cancer cell lines. For LNCaP, the hormone-dependent pathway is believed to involve its cytotoxicity.

Cytotoxic activity induced by p53 and SIRT1 gene expression

Normally inactivated in cells by its negative regulators, tumor-related protein $\mathrm{p} 53$, encoded by a tumor suppressor gene, frequently mutates during cancer development. In Figure 5, p53 gene expression was significantly up-regulated in T24 and down-regulated in HUVEC. In contrast, Figure 6 revealed that SIRT1 gene expression was significantly down-regulated in T24 and up-regulated in HUVEC.

\section{Discussion}

Phytochemical study indicated the difference in compositions between aqueous and ethanol extract. Brief fingerprint profiles from TLC will be implemented as a reference for raw-material quality control and an explanation for different physiological and pharmacological effects found in future studies.

Dose- and time-dependent manners of T24 response are shown in Figure 2. The obviously low $\mathrm{IC}_{50}$ value of ethanol KP extract after receiving treatment for 1, 4 and 7 days indicates a higher potency. In general, low $\mathrm{IC}_{50}$ value

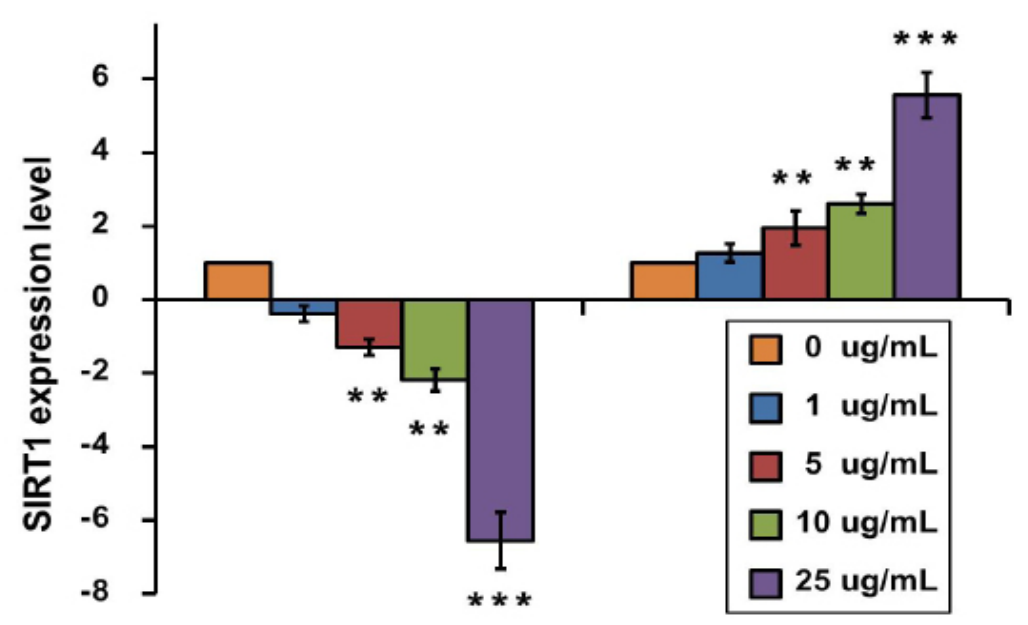

Figure 6. Cells Treated with Ethanol KP Extract for 4 Days Significantly Show Down-Regulation and Up-Regulation of SIRT1 Gene in T24 and HUVEC, respectively. Data are expressed in mean \pm SD of three independent experiments. Statistical significance is determined by $* * p<0.01$ and $* * * p<0.001$. 


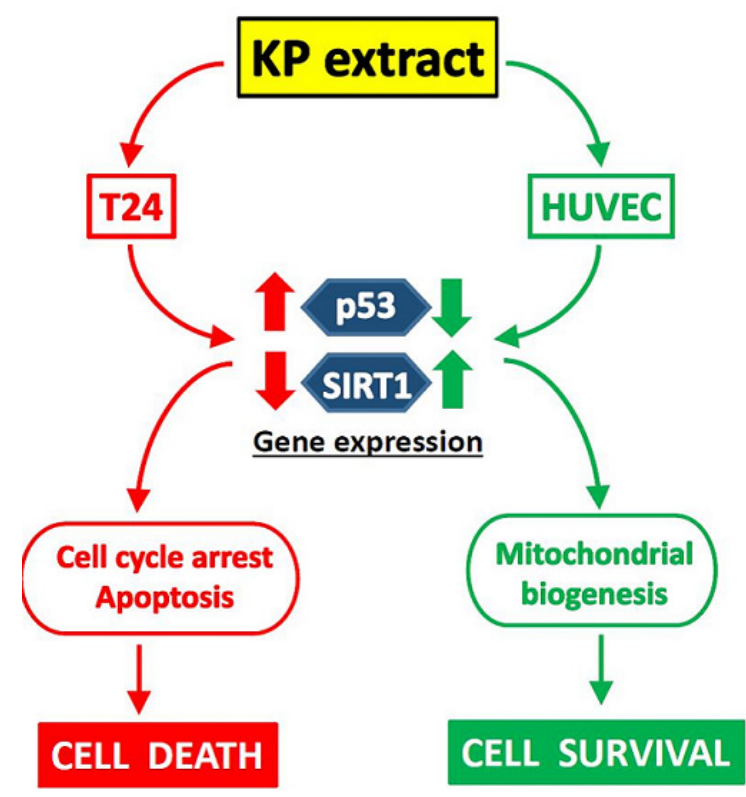

Figure 7. Flowchart Illustrating the Proposed Mechanisms of Ethanol KP Extract in Cancer (Human urinary bladder cancer cell, T24) and Normal Cell Lines (Human umbilical vein endothelial cell, HUVEC)

implies that a compound possesses high cytotoxicity and potency. Thus therapeutic dose for that compound will be low if implemented in clinical settings. For all of the following experiments, the authors solely used ethanol extract.

Regarding selective activity to cancerous cells, Figure 3 shows that T24 has approximately 3-7 times lower $\mathrm{IC}_{50}$ value than that of HUVEC. This evidence possibly suggests a selective effect of ethanol KP extract to bladder cancer cell line. The gap difference of $\mathrm{IC}_{50}$ value between HUVEC and T24 may not be sufficient to confirm the safety of ethanol KP extract in endothelial cells. Considering its low oral bioavailability of 1 to $4 \%$ reported in rats, toxic dose of KP extract in endothelial cells can be very difficult to identify (Mekjaruskul et al., 2012). However, current pharmaceutical studies have been trying to improve the dissolution rate, drug permeability and bioavailability of methoxyflavones in KP (Mekjaruskul et al., 2013; Tuntiyasawasdikul et al., 2014; Chairuk et al., 2020).

In addition, ethanol KP extract also exerts anti-proliferative activity in three prostate cancer cell lines with different metastatic potential. Lower $\mathrm{IC}_{50}$ value was detected in lowly metastatic cells, DU145, while higher $\mathrm{IC}_{50}$ value was found in highly metastatic cells, PC3. Supported by Paramee et al., 2018, high $\mathrm{IC}_{50}$ value was reported in human ovarian cancer cell line, SKOV3, which is known as a high-grade serous adenocarcinoma with a high metastatic rate. The reason for high cytotoxicity in LNCaP may involve a hormone-dependent pathway. This is consistent with the previous KP extract report mentioning suppression of benign prostate hyperplasia by potent inhibition of $5 \alpha$-reductase (Murata et al., 2013).

Previous studies usually reported anti-proliferative activity in $\mathrm{IC}_{50}$ ranging from 0 to $100 \mu \mathrm{g} / \mathrm{mL}$ (Banjerdpongchai et al., 2008; Banjerdpongchai et al.,
2009; Leardkamolkarn et al., 2009; Potikanond et al., 2017; Kim et al., 2018; Paramee et al., 2018) which is the same as $\mathrm{IC}_{50}$ range found in the present study.

Cellular mechanism of KP extract remains unknown. General cellular mechanism was screened using gene expression analysis of $p 53$ and SIRT1. P53, classified as a tumor suppressor gene, plays a crucial role in stabilizing other genes by preventing DNA mutations. Previously, $\mathrm{KP}$ extract has been reported to inhibit the expression of cell-cycle inhibitors including p53 in normal cells and human dermal fibroblasts (Park et al., 2017). Inhibition of 553 expression might possibly involve in cell survival. Moreover, KP extract also induces SIRT1 expression, a gene involving several important biological controls, which facilitates mitochondrial biogenesis to prolong cellular life span (Bai et al., 2018; Vargas-Ortiz et al., 2019). This might be the cause of higher $\mathrm{IC}_{50}$ value in HUVEC.

Figure 7 summarizes proposed mechanisms of ethanol KP extract in both T24 and HUVEC. For T24 cell line, ethanol KP extract up-regulated $p 53$ and down-regulated SIRT1 gene. As a result, $\mathrm{IC}_{50}$ value decreases and selective anti-proliferative activity is introduced. Apoptosis induction was also found in other cancerous cells including human ovarian cancer SKOV3 cell line (Paramee et al., 2018), human leukemic U937 cell line (Banjerdpongchai et al., 2009), and human bile duct cancer RMCCA-1 cell line (Leardkamolkarn et al., 2009).

In conclusion, compared to the aqueous version, ethanol KP extract exhibits higher anti-proliferative effect, hypothesized to be via $p 53$ and SIRT1 gene expression, specifically to cancerous cells which is approximately 5-7 times more than normal or endothelial cells. Moreover, low bioavailability of methoxyflavones suggests its safety for consumers who may select pharmaceutical or supplementary products containing KP extracts.

\section{Acknowledgments}

This study is financially supported by a grant from HRH Princess Maha Chakri Sirindhorn Medical Center (MSMC), Faculty of Medicine, Srinakharinwirot University, Thailand.

\section{Conflict of Interest}

The authors confirm that there is no conflict of interest to declare.

\section{References}

Akase T, Shimada T, Terabayashi S, et al (2011). Antiobesity effects of Kaempferia parviflora in spontaneously obese type II diabetic mice. $J$ Nat Med, 65, 73-80.

Alimirah F, Chen J, Basrawala Z, Xin H, Choubey D (2006). DU-145 and PC-3 human prostate cancer cell lines express androgen receptor: Implications for the androgen receptor functions and regulation. FEBS Lett, 580, 2294-300.

Bai X, Yao L, Ma X, Xu X (2018). Small molecules as SIRT modulators. Mini Rev Med Chem, 18, 1151-7.

Banjerdpongchai R, Chanwikruy Y, Rattanapanone V, Sripanidkulchai B (2009). Induction of apoptosis in the human leukemic U937 cell line by Kaempferia parviflora 
Wall. ex. Baker extract and effects of paclitaxel and camptothecin. Asian Pac J Cancer Prev, 10, 1137-40.

Banjerdpongchai R, Suwannachot K, Rattanapanone V, Sripanidkulchai B (2008). Ethanolic rhizome extract from Kaempferia parviflora Wall. ex. Baker induces apoptosis in HL-60 cells. Asian Pac J Cancer Prev, 9, 595-600.

Chairuk P, Tubtimsri S, Jansakul C, Sriamornsak P, Weerapol Y (2020). Enhancing oral absorption of poorly water-soluble herb (Kaempferia parviflora) extract using self-nanoemulsifying formulation. Pharm Dev Technol, 25, 340-50.

Chen D, Li H, Li W, Feng S, Deng D (2018). Kaempferia parviflora and its methoxyflavones: chemistry and biological activities. Evid Based Complement Alternat Med, 2018, 4057456.

Chivapat S, Chavalittumrong P, Attawish A, Rungsipipat A (2010). Chronic toxicity study of Kaempferia parviflora Wall ex. Extract. Thai J Vet Med, 40, 377-83.

Kim H, Moon JY, Burapan S, Han J, Cho SK (2018). Induction of ER stress-mediated apoptosis by the major component 5,7,4'-trimethoxyflavone isolated from Kaempferia parviflora tea infusion. Nutr Cancer, 70, 984-96.

Leardkamolkarn V, Tiamyuyen S, Sripanidkulchai BO (2009). Pharmacological activity of Kaempferia parviflora extract against human bile duct cancer cell lines. Asian Pac J Cancer Prev, 10, 695-8.

Liu AY (2000). Differential expression of cell surface molecules in prostate cancer cells. Cancer Res, 60, 3429-34.

Matsuda H, Nakamura S, Yoshikawa M (2014). Search for new type of PPAR $\gamma$ agonist-like anti-diabetic compounds from medicinal plants. Biol Pharm Bull, 37, 884-91.

Mekjaruskul C, Jay M, Sripanidkulchai B (2012). Pharmacokinetics, bioavailability, tissue distribution, excretion, and metabolite identification of methoxyflavones in Kaempferia parviflora extract in rats. Drug Metab Dispos, 40, 2342-53.

Mekjaruskul C, Yang YT, Leed MG, et al (2013). Novel formulation strategies for enhancing oral delivery of methoxyflavones in Kaempferia parviflora by SMEDDS or complexation with 2-hydroxypropyl- $\beta$-cyclodextrin. Int $J$ Pharm, 445, 1-11.

Murata K, Hayashi H, Matsumura S, Matsuda H (2013). Suppression of benign prostate hyperplasia by Kaempferia parviflora rhizome. Pharmacognosy Res, 5, 309-14.

Ninomiya K, Matsumoto T, Chaipech S, et al (2016). Simultaneous quantitative analysis of 12 methoxyflavones with melanogenesis inhibitory activity from the rhizomes of Kaempferia parviflora. J Nat Med, 70, 179-89.

Paramee S, Sookkhee S, Sakonwasun C, et al (2018). Anti-cancer effects of Kaempferia parviflora on ovarian cancer SKOV3 cells. BMC Complement Altern Med, 18, 178.

Park JE, Woo SW, Kim MB, Kim C, Hwang JK (2017). Standardized Kaempferia parviflora extract inhibits intrinsic aging process in human dermal fibroblasts and hairless mice by inhibiting cellular senescence and mitochondrial dysfunction. Evid Based Complement Alternat Med, 2017, 6861085.

Patanasethanont D, Nagai J, Matsuura C, et al (2007a). Modulation of function of multidrug resistance associated-proteins by Kaempferia parviflora extracts and their components. Eur $J$ Pharmacol, 566, 67-74.

Patanasethanont D, Nagai J, Yumoto R, et al (2007b). Effects of Kaempferia parviflora extracts and their flavone constituents on P-glycoprotein function. J Pharm Sci, 96, 223-33.

Potikanond S, Sookkhee S, Na Takuathung M, et al (2017). Kaempferia parviflora extract exhibits anti-cancer activity against HeLa cervical cancer cells. Front Pharmacol, 8, 630 .
Promthep K, Eungpinichpong W, Sripanidkulchai B, Chatchawan U (2015). Effect of Kaempferia parviflora extract on physical fitness of soccer players: a randomized double-blind placebo-controlled trial. Med Sci Monit Basic Res, 21, 100-8.

Ravenna L, Principessa L, Verdina A, et al (2014). Distinct phenotypes of human prostate cancer cells associate with different adaptation to hypoxia and pro-inflammatory gene expression. PLoS One, 9, e96250.

Saokaew S, Wilairat P, Raktanyakan P, et al (2017). Clinical effects of krachaidum (Kaempferia parviflora): A systematic review. J Evid Based Comp Altern Med, 22, 413-28.

Shimada T, Horikawa T, Ikeya Y, et al (2011). Preventive effect of Kaempferia parviflora ethyl acetate extract and its major components poly-methoxyflavonoid on metabolic diseases. Fitoterapia, 82, 1272-8.

Songpol C, Pranee C, Aimmanas A, Anudep R (2010). Chronic study of Kaempferia parvifloraWall ex. Extract. Thai J Vet Med, 40, 377-83.

Sutthanut K, Sripanidkulchai B, Yenjai C, Jay M (2007). Simultaneous identification and quantitation of 11 flavonoid constituents in Kaempferia parviflora by gas chromatography. J Chromatogr A, 1143, 227-33.

Tuntiyasawasdikul S, Limpongsa E, Jaipakdee N, et al (2014). Transdermal permeation of Kaempferia parviflora methoxyflavones from isopropyl myristate-based vehicles. AAPS Pharm Sci Tech, 15, 947-55.

Vargas-Ortiz K, Pérez-Vázquez V, Macías-Cervantes MH (2019). Exercise and sirtuins: A way to mitochondrial health in skeletal muscle. Int J Mol Sci, 20, pii: E2717.

Wattanathorn J, Muchimapura S, Tong UT, et al (2012). Positive modulation effect of 8-week consumption of Kaempferia parviflora on health-related physical fitness and oxidative status in healthy elderly volunteers. Evid Based Complement Alternat Med, 2012, 732816.

Yahayo W, Supabphol A, Supabphol R (2013). The in vitro metastatic suppression of Phyllanthus emblicaextract on human fibrosarcoma cells. Asian Pac J Cancer Prev, 14, 6863-7.

Yoshino S, Kim M, Awa R, et al (2014). Kaempferia parviflora extract increases energy consumption through activation of BAT in mice. Food Sci Nutr, 2, 634-7.

Yoshino S, Awa R, Miyake Y, et al (2018). Daily intake of Kaempferia parviflora extract decreases abdominal fat in overweight and pre-obese subjects: a randomized, double-blind, placebo-controlled clinical study. Diabetes Metab Syndr Obes, 11, 447-58.

Yoshino S, Awa R, Ohto N, Miyake Y, Kuwahara H (2019). Toxicological evaluation of standardized Kaempferia parviflora extract: Sub-chronic and mutagenicity studies. Toxicol Rep, 6, 544-9.

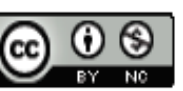

This work is licensed under a Creative Commons AttributionNon Commercial 4.0 International License. 